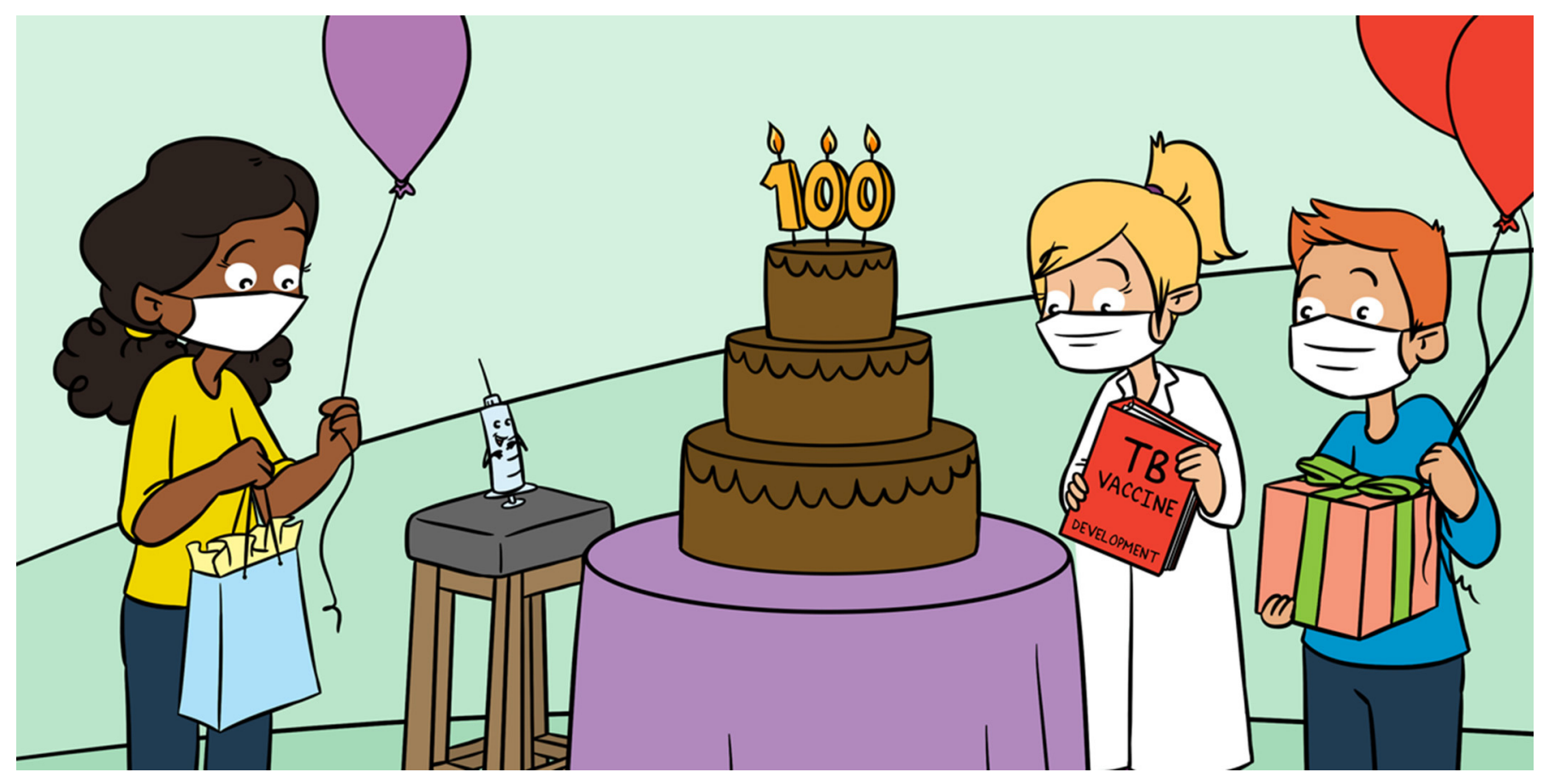

\title{
ONE HUNDRED YEARS OF BCG: THE WORLD'S MOST WIDELY USED VACCINE
}

\section{Rachel Tanner* and Helen McShane}

The Jenner Institute, Nuffield Department of Medicine, University of Oxford, Oxford, United Kingdom

\section{YOUNG REVIEWER:}

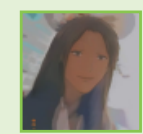

APARNA

AGE: 12
VACCINE

A product that

stimulates a person's

immune system to

produce immunity to a

specific disease,

protecting them from

that disease.
2021 is the 100-year anniversary of the BCG vaccine, and there is a lot to celebrate! This vaccine has without doubt saved the lives of millions of people, by protecting them from the bacterial lung disease tuberculosis (TB) and possibly other illnesses too. However, there are some drawbacks to BCG-in particular, it does not work very well in some countries that have high rates of TB, so a new and improved vaccine is desperately needed. Scientists around the world are working hard to develop a new TB vaccine, but there are challenges. If we can better understand how BCG works and why it works in some populations and not others, it might help us to design a better vaccine to protect people against tuberculosis and to possibly one day eradicate this disease.

\section{THE BCG VACCINE PROTECTS AGAINST TUBERCULOSIS}

You might already know that a vaccine is a type of medicine, often given as an injection, that prevents infection or disease. The BCG 
BCG

The only vaccine that currently exists against tuberculosis, named after its inventors Albert Calmette and Camille Guérin.

\section{TUBERCULOSIS}

A bacterial infection that usually affects the lungs, and is spread in the air through coughs and sneezes.

\section{ANTIBIOTICS}

Medicines designed to treat infections caused by bacteria. vaccine is designed to protect against tuberculosis (TB), which is a bacterial disease that usually affects the lungs and causes a serious cough. TB has existed for thousands of years-signs of TB have even been found in Egyptian mummies from around 3000 BCE! TB is also one of the most common infectious diseases in the world, with a quarter of the world's population infected. Almost 1.5 million people die from TB every year, and it can be particularly dangerous in babies [1].

One hundred years ago, two French scientists named Albert Calmette and Camille Guérin invented a vaccine against TB. They called it BCG, which is short for Bacillus Calmette-Guérin. It is made from the bacteria that causes the cow version of TB, and Calmette and Guérin altered the bacteria to make sure the vaccine would not cause disease in humans. Since then, BCG has been the most widely used vaccine ever, with around 100 million babies receiving it every year.

\section{PROS OF THE BCG VACCINE}

The BCG vaccine has been given to over 4 billion people and has been shown to be very safe. Some people get mild side effects, such as a headache or fever and a blister or sore arm where the injection went in. However, more serious side-effects are very rare.

When the BCG vaccine is given to new-born babies, it provides excellent protection against serious forms of TB-for example, TB that spreads to the brain (called TB meningitis) and TB that spreads throughout the body (called miliary TB). Because these forms of TB have a high risk of death, BCG is really effective in reducing the death rate from TB. The most common type of TB is disease of the lungs, and BCG is good at protecting against this in some countries, such as the U.K. [2].

Although antibiotics have been developed to treat TB, prevention with a vaccine is better than treatment. If you can stop people from becoming sick in the first place, they will not suffer from the symptoms or risk dying. In addition, in countries that have high rates of TB, antibiotics are often too expensive or difficult to access. Some types of TB bacteria have evolved resistance against antibiotics, so these treatments are no longer effective.

BCG can protect against other diseases as well as TB. For example, it provides some protection against leprosy, which is a disease caused by bacteria that are related to the TB bacteria. Leprosy often causes patches or rashes on the skin and can lead to people being stigmatized. In the past, people with leprosy were even banished to "leper colonies," or islands away from everyone else. There is also some evidence that the BCG vaccine may protect babies against other illnesses that are not related to TB at all. A recent study in Uganda showed that babies 


\section{Figure 1}

The BCG vaccine has many advantages.

\section{IMMUNE SYSTEM}

The organs and cells of the body that fight against infections and toxins to provide resistance against getting sick.

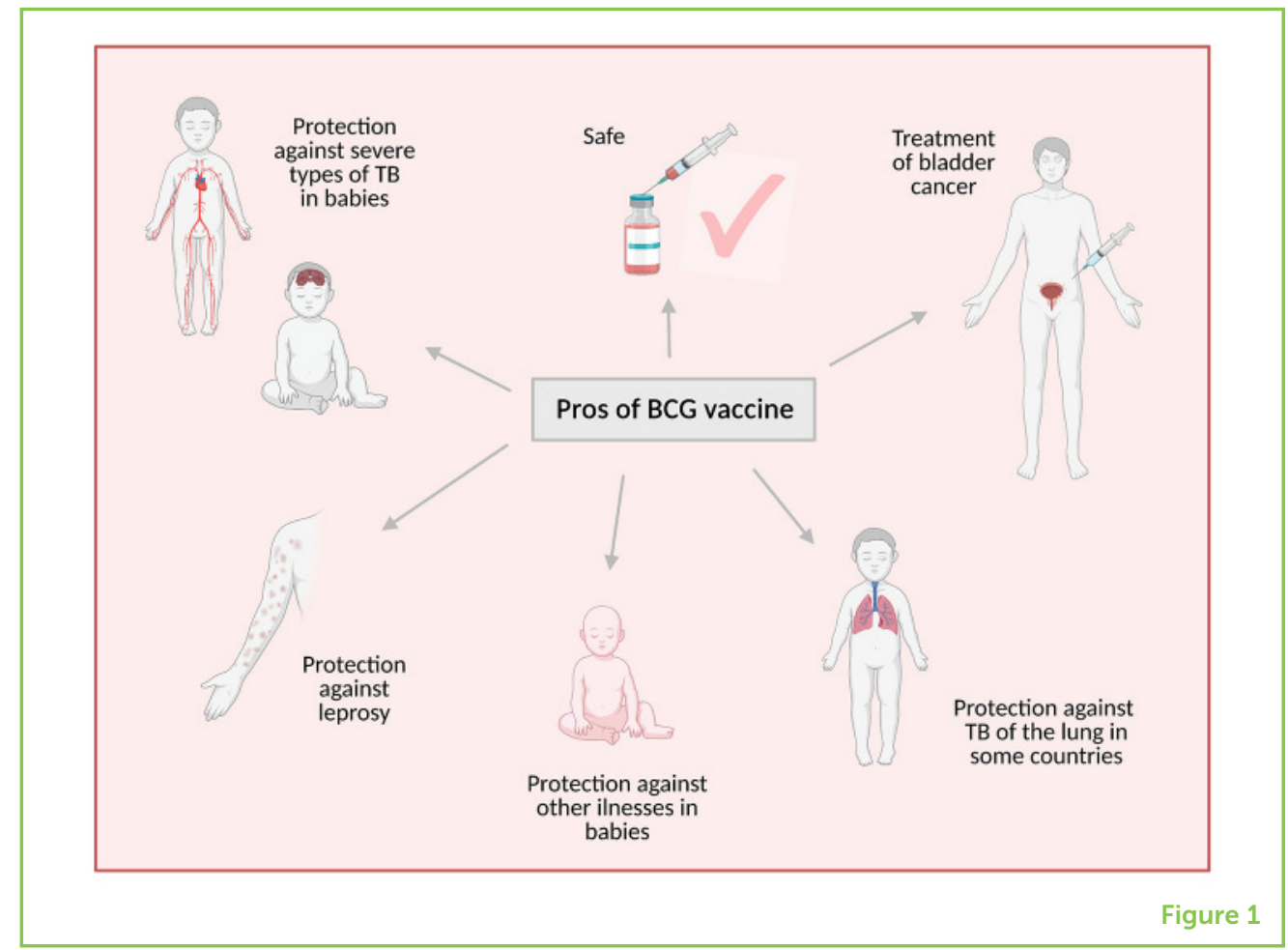

who received the BCG vaccine as soon as they were born were less likely to get ill in general than were babies who got their BCG vaccine at 6 weeks old [3].

BCG has another use you might find surprising-it can be given as a treatment for bladder cancer [4]. Scientists are still trying to figure out why BCG is effective at treating this disease, but it is thought that it might improve the ability of immune cells to kill cancer cells. The pros of BCG are summarized in Figure 1.

\section{CONS OF THE BCG VACCINE}

There are some situations in which the BCG vaccine should not be given. For example, BCG is not considered safe to give to babies or adults who are infected with HIV (a virus that attacks cells of the immune system), because the BCG vaccine is made from live bacteria. Although Calmette and Guérin tweaked the bacteria so that they would not cause disease, people with HIV or certain other disorders have weakened immune systems that BCG can overcome and make them sick.

BCG is very effective at protecting children against TB in some countries, such as the UK, but not very effective in others. It provides low levels of protection, or even no protection, in places such as India and sub-Saharan Africa [2]. Unfortunately, these are the areas with high rates of TB, where a vaccine is needed the most (Figure 2). Scientists still do not fully understand why BCG works differently in 
Figure 2

The BCG vaccine provides varying levels of protection against lung TB in different countries. While the vaccine protects over $75 \%$ of vaccinated people in areas like the UK, the efficacy (effectiveness) of the vaccine decreases in the regions close to the equator (shown in red) [2].

\section{BOOSTER}

A booster is a second vaccination given against the same infection or disease to try to "boost" protection provided by the first vaccination.

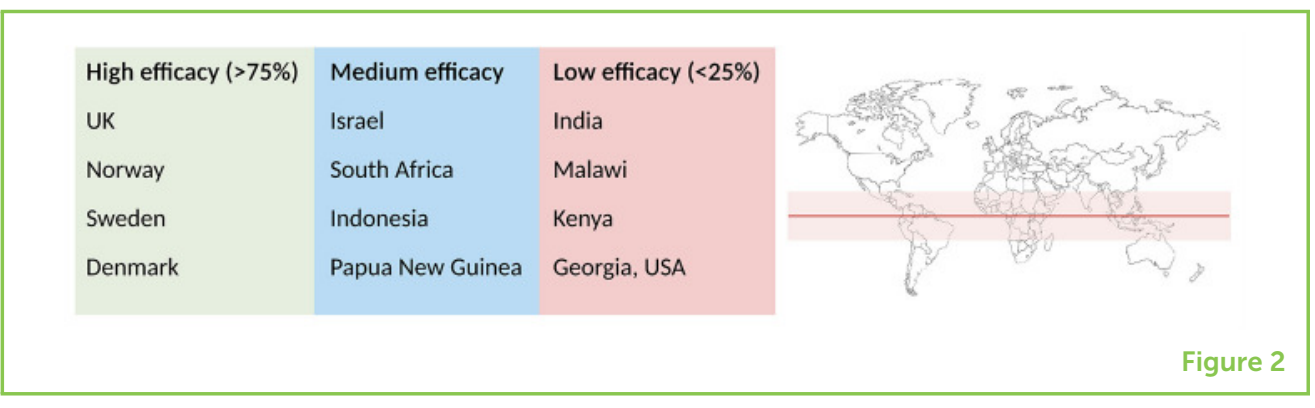

different countries, but most think it has to do with the presence of other bacteria that are related to TB. The closer you get to the equator, the more of these TB-related bacteria are found in the environment. If people are living with these bacteria around them, their bodies develop an immune response to the bacteria that might interfere with the BCG vaccine working properly.

Other reasons scientists have suggested for BCG working differently in different populations include differences in the specific version of the vaccine used, the ability to keep the vaccine refrigerated, differences in people's genetics or nutritional status, environmental influences such as the amount of sunlight exposure, or viral infections that are present when BCG is given (Figure 3).

\section{NEW TB VACCINES}

Because of these drawbacks of the BCG vaccine, a new and improved TB vaccine is desperately needed to bring TB under control. However, we need to make sure we do not lose the advantages of BCG. Scientists around the world are working hard to design and test new TB vaccines and there are several that look promising [5]. The main approaches are to try to improve on BCG through altering the genes of the bacteria, or to give a new vaccine as a booster to BCG. Researchers in Spain have been modifying human TB bacteria to make them as safe as BCG, and they are now testing this vaccine in human volunteers.

However, in the 100 years since BCG was developed, we still do not have a new TB vaccine approved for use. If you think about the new vaccines for COVID-19, it took less than a year to go from initial design to mass vaccination, so why is it so much harder for TB? One of the challenges is that we do not know which parts of the immune system are important to protect us from TB, which makes it difficult to design the vaccine and check whether it is working. We also do not have reliable ways to test the vaccine. It is not ethical to infect people with TB after giving them the vaccine, so testing needs to be done in animals instead. However, animals might not be a good representation of what happens in humans. 
Figure 3

Scientists are still not sure why the BCG vaccine works better in some populations than others, but there are several possible reasons.

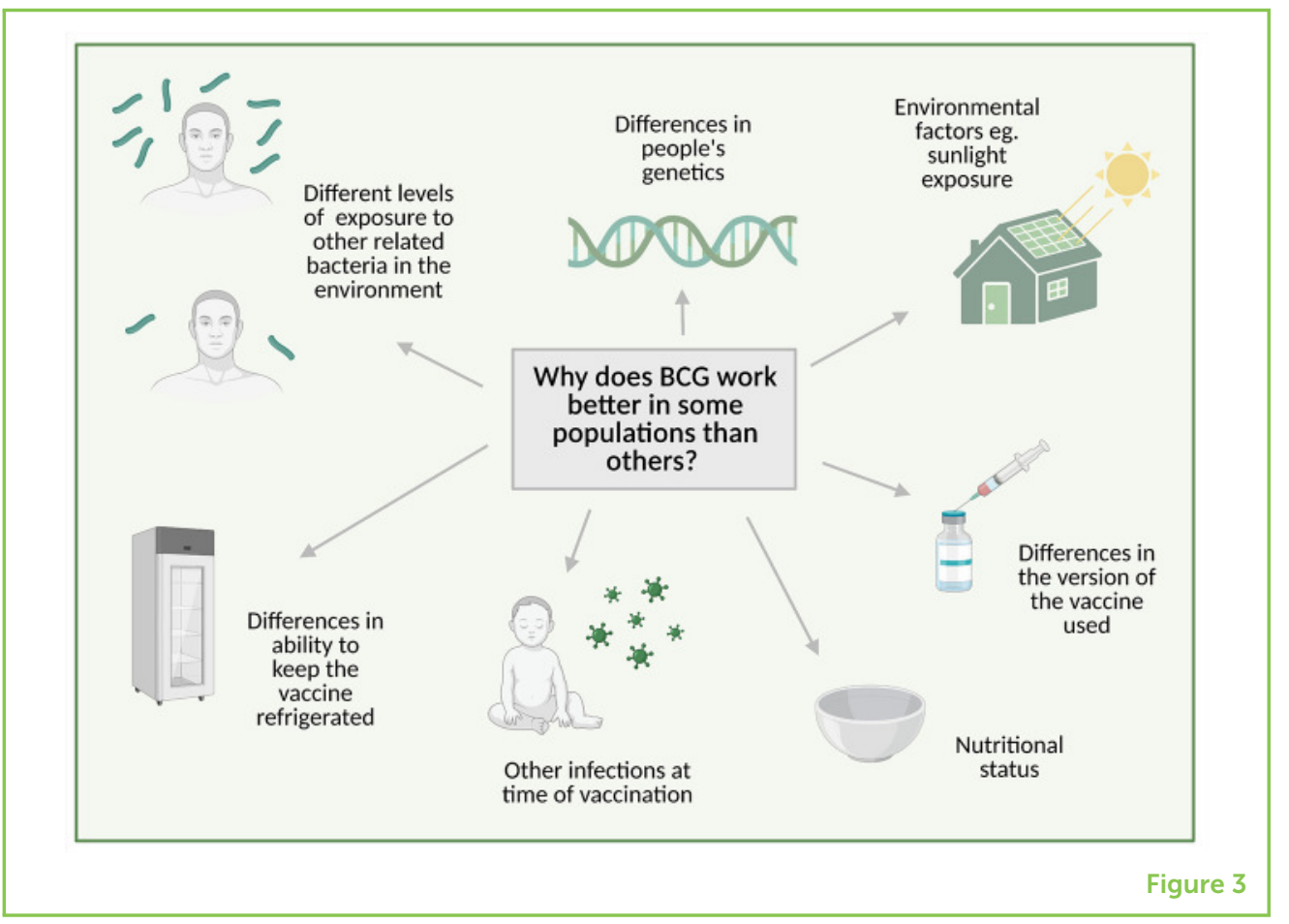

At the University of Oxford, our research aims to address some of these issues. For example, we are studying how the immune system reacts to $B C G$ vaccination, to understand which types of immune responses protect people from TB and which parts of the bacteria the immune system targets. We are designing new vaccines based on these findings. We are also developing alternative ways to test TB vaccines: either by infecting people with safe bacteria that are related to TB, or by infecting cells in a test-tube as a model of what happens inside the body. If we can better understand how the BCG vaccine provides protection from TB, and why it works in some populations and not others, it might help us to design a better TB vaccine in the future.

\section{CONCLUSION}

2021 marks 100 years of the BCG vaccine, which is designed to protect against tuberculosis. This vaccine has been given to over 4 billion people. BCG is safe and offers many advantages, including protecting babies against serious forms of TB disease, protecting people in some countries against TB of the lungs, and reducing the risk of other related illnesses such as leprosy and maybe even unrelated illnesses like pneumonia. It is also used as a treatment for bladder cancer. However, BCG does not work very well in some of the countries that have high rates of TB and that are most in need of a vaccine. TB remains a major global health issue and scientists around the world are working to develop a new and improved TB vaccine, although there are many challenges involved. Better understanding of BCG might give 
us the clues we need to design a vaccine that protects everybody and eventually eradicates TB once and for all.

\section{ACKNOWLEDGMENTS}

We would like to thank the UKRI-GCRF network VALIDATE for coordinating the BCG100 outreach programme and funding aspects of our research to develop a new TB vaccine. Figures were created with BioRender.com.

\section{REFERENCES}

1. WHO. 2020. Global Tuberculosis Report 2020. Geneva: World Health Organisation.

2. Fine, P. E. 1995. Variation in protection by BCG: implications of and for heterologous immunity. Lancet 346:1339-45. doi: 10.1016/S0140-6736(95) 92348-9

3. Prentice, S., Nassanga, B., Webb, E. L., Akello, F., Kiwudhu, F., Akurut, H., et al. 2021. BCG-induced non-specific effects on heterologous infectious disease in Ugandan neonates: an investigator-blind randomised controlled trial. Lancet Infect. Dis. doi: 10.1016/S1473-3099(20)30653-8

4. Alexandroff, A. B., Jackson, A. M., O'Donnell, M. A., and James, K. 1999. BCG immunotherapy of bladder cancer: 20 years on. Lancet 353:1689-94. doi: 10.1016/S0140-6736(98)07422-4

5. Tanner, R., and McShane, H. 2020. "BCG and other vaccines," in Cinical Tuberculosis, 6th Edn., eds L. N. Friedman, M. Dedicoat, and P. D. Davies (Boca Raton, FL: CRC Press).

SUBMITTED: 15 March 2021; ACCEPTED: 07 June 2021;

PUBLISHED ONLINE: 01 July 2021.

EDITED BY: Michel Goldman, Institute for Interdisciplinary Innovation in healthcare (I3h), Belgium

CITATION: Tanner R and McShane H (2021) One Hundred Years of BCG: The World's Most Widely Used Vaccine. Front. Young Minds 9:681024. doi: 10.3389/ frym.2021.681024

CONFLICT OF INTEREST: The authors declare that the research was conducted in the absence of any commercial or financial relationships that could be construed as a potential conflict of interest.

COPYRIGHT @ 2021 Tanner and McShane. This is an open-access article distributed under the terms of the Creative Commons Attribution License (CC BY). The use, distribution or reproduction in other forums is permitted, provided the original author(s) and the copyright owner(s) are credited and that the original publication in this journal is cited, in accordance with accepted academic practice. No use, distribution or reproduction is permitted which does not comply with these terms. 


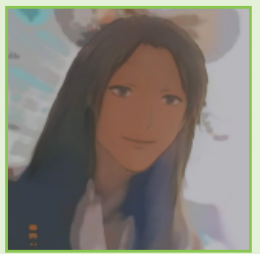

\section{YOUNG REVIEWER}

\section{APARNA, AGE: 12}

I am a 12 year old girl and my interests are science, music and art! I am also a sports enthusiast who loves any type of action. Other interests include playing violin, drawing and making new friends. I love the Harry Potter book series and the movies as well. My dream is to become a neurologist 1 day and help find cures to diseases.
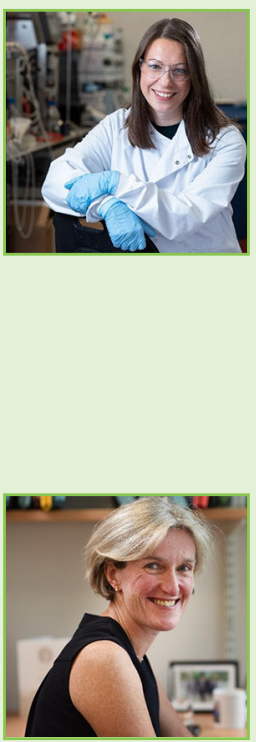

\section{AUTHORS}

\section{RACHEL TANNER}

I am a post-doctoral research fellow and lecturer in human sciences at the University of Oxford. I became a medical scientist because I was shocked by how many people are still getting sick and dying every day from diseases like tuberculosis and HIV. I wanted to do something to help, and as everyone knows, prevention is better than cure-so I started working on vaccines. I now study the immune response to TB and try to develop new ways of testing vaccines instead of using animals for experiments. During my free time, I enjoy playing polo and have recently taken up beekeeping! *rachel.tanner@ndm.ox.ac.uk

\section{HELEN MCSHANE}

I am a professor of vaccinology, consultant physician, deputy head for the Medical Sciences Division and director of the Biomedical Research Center in Oxford. I have led a TB vaccine research group at the Jenner Institute, University of Oxford for the last 20 years. One important aspect of that has been the development of MVA85A-the first new TB vaccine candidate to enter efficacy testing. One of the current focusses of my work is developing TB vaccines that are inhaled rather than injected. I enjoy spending time with my three children and our dog Archie, and swim whenever I get the chance. 